\title{
Reliability Analysis of Secondary Distribution System in Nigeria: A Case Study of Ayetoro 1 Substation, Lagos State.
}

\author{
Ayodeji A. Akintola, Claudius Ojo A. Awosope \\ Department of Electrical and Information Engineering, Covenant University
}

\begin{abstract}
-
A power system is set up basically to meet the demands of the customers. However, interruptions which are largely unavoidable contribute to the unavailability of power and thus prevent power system from achieving this. In most cases, it is the sustained interruptions that greatly affect both the utility company and its customers. Hence, it is necessary to find means of determining which component failure contributes most to the unavailability of the distribution system, and how this unavailability actually affects the customers. This is to enable system planners and designers to seek better ways of improving the reliability of a typical secondary distribution substation system having a single-end fed radial configuration. By using analytical method and network reduction technique, the substation reliability was analyzed based on the outage data gotten from the utility company. The conclusion from this work shows that transformer failure followed by fuse failure contributes most to the substation's unavailability. The overall system availability shows that the system's performance is poor.
\end{abstract}

Keywords: Interruptions, Unavailability, Component failure, Reliability indices, Distribution system.

\section{INTRODUCTION}

An electric power system is basically established to supply electricity with little or no interruptions to its customers. The number of interruptions that occur while the system performs its intended function is part of what determines the overall reliability of the system. The other factor that determines its reliability is the quality of electricity delivered. Furthermore, the capability of a power system to continuously deliver quality electricity means that the customers are satisfied and the electricity providers are having favourable returns on their investment as they continue their business of supplying electricity. As electricity consumption has become an important factor that affects the drive needed for technology to grow and to facilitate the development of modern society, it is very important therefore to take seriously the issue of reliability of an electric power system.

Generation, transmission and distribution are the three subsystems an electric power system is divided into. At the generating station, electricity is generated and transmitted through the high voltage transmission lines to the distribution substations. The distribution substation system considered covers the electrical system between the substation fed by the subtransmission system and the supply line to the consumers' meters i.e. $11 \mathrm{kV}$ to $0.415 \mathrm{kV}$ transformation [1]. These distribution substations are usually sited relatively near the consumers for effective delivery, monitoring and maintenance of the substation and the consumer end and are usually referred to as secondary distribution substation system or consumer substation. Distribution systems basically serve as the link from the distribution substation to the customer. Reliable and safe transfer of electricity to the customers covered by the distribution area is ensured by this system.

In terms of reliability evaluation and modelling, generating stations have justifiably received more attention than the other systems because they are individually capital intensive. In addition, inadequate and loss of generation impacts directly on the whole system and even distribution system will not be able to perform its duty because there will be no electricity to supply to consumers [2]. However based on published research work and studies, distribution systems have begun to receive moderate attention compared to past decades. In most cases, when there is disturbance in form of failure which results in outages in the distribution system it affects only the localized territory. Only in few cases does the fault move up in to the system largely as a result of protection failure. Analysis of the consumer failure statistics of most electricity companies shows that the distribution system makes the greatest individual contribution to the unavailability of supply to a consumer [3]. In effect, the purpose of establishing generating stations and the hurdles overcome to transmit electricity is defeated when it 
does not get to the user end as a result of distribution system failure. This makes distribution system to be highly important. The distribution systems account for up to $90 \%$ of all consumer reliability problems, improving distribution reliability is the key to improving customer reliability [4].

Since the primary purpose of the system is to satisfy consumer requirements and the proper functioning and longevity of the system are essential requisites for continued satisfaction, it is necessary that both demand and supply considerations are appropriately viewed and included in the systems. Therefore, the distribution reliability is one of the most important in the electric power industry due to its high impact on the cost of electricity and its high correlation with consumer satisfaction. This paper focuses on the substation's inability to deliver electricity as a result of its own deficiency when there is electricity available for distribution.

\section{METHOD}

Quantitative technique, which involves collection of data, is used for this work. This technique describes the historical performance of existing systems and utilizes the historical performance to predict the effects of changing conditions on system performance. The reliability indices of the substation were computed using the twelve-month data collected on the system. In most cases, distribution systems are operated in a radial configuration [5] and the secondary distribution studied has such configuration which is typical of most substations in Nigeria i.e. single-end fed radial configuration as shown in Fig. 2. Moreover, a radial system basically consists of set of series components such as breakers, lines, switches, transformers and at the end "Consumers" [6].

From reliability viewpoint, all the components in a series system must be working together to ensure system success or else the failure of one component leads to the entire system's failure. This therefore implies that a series system is a non- redundant system. Network reduction method is used because the system has one common mode of failure i.e. the failure of one component leads to interruption. Also, by using some reliability parameters, the overall system availability is assessed. The system reliability indices such as SAIFI, SAIDI, CAIDI, ASAI and ASUI are used to calculate the contribution of loss of supply to the consumers.

Figure 1 below describes a series system:

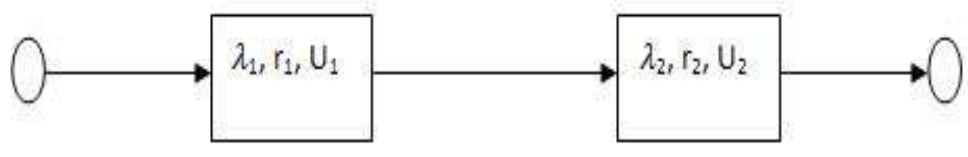

Figure 1

$$
\begin{aligned}
& \lambda_{s}=\lambda_{1}+\lambda_{2}=\sum_{i=1}^{2} \lambda_{i} \\
& U_{s}=\lambda_{1} r_{1}+\lambda_{2} r_{2}=\sum_{i=1}^{2} \lambda_{i} r_{i} \\
& r_{s}=\frac{U_{g}}{\lambda_{g}}
\end{aligned}
$$

\section{EQUATIONS}

A common way of defining reliability is in terms of consumer and load-based indices [3]. References [2], [7] provided the indices used in the calculations:

$$
\begin{aligned}
& \text { System Average Interruption Duration index (SAIDI) } \\
& \text { It is expressed as } \\
& \text { SAIDI }=\frac{\text { Total Outage Duration in hours }}{\text { Number of Consumers Supplied }} \\
& \text { System Average Interruption Frequency index (SAIFI) } \\
& \text { It is expressed as } \\
& \qquad \text { SAIFI }=\frac{\text { Frequency of Outages }}{\text { Number of Consumers Supplied }}
\end{aligned}
$$


Customer Average Interruption Duration Index (CAIDI)

It is expressed as

$$
C A I D I=\frac{\text { Sum of Consumer Interruption Durations }}{\text { Total number of Consumers Interrupted }}=\frac{\text { SAIDI }}{\text { SAIFI }}
$$

The Average Service Availability Index (ASAI)

It is expressed as

$$
\text { ASAI }=\frac{\text { Consumers Hours Service Availability }}{\text { Consumers Hours service Demanded }}
$$

Average Service Unavailability Index (ASUI)

It is expressed as

$$
\text { ASUI }=\frac{\text { Duration of Outages in Hours }}{\text { Total Hours Demanded }}
$$

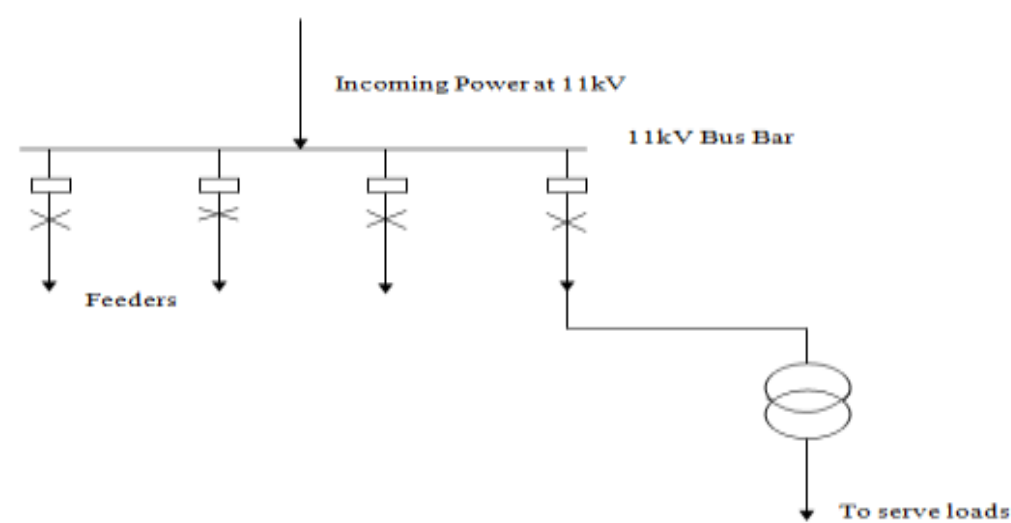

$\underline{\text { Legend }}$

Overcurrent and Earth Fault protection

Circuit Breaker

Distribution Transformer

Figure 2: A Typical Single-End Radial Network Configuration

\subsection{COLLECTION OF DATA}

The data collected was for twelve-month component outage duration. Outages on the components listed below were recorded in the utility outage logbook as a result of consumers' complaints to the utility company. The substation system, like other substations in Nigeria and other lower middle income countries, does not have intelligent devices that can alert the distribution company whenever there is failure of any equipment or any form of interruption to the delivery of electricity to the consumer. Furthermore, only forced outages, outages due to faults and failures which led to sustained interruption were taken into consideration for this study to avoid extraneous circumstances. Outages due to scheduled maintenance and load shedding were not taken into consideration. This is so because scheduled outage or load shedding in the substation is intentional and cannot be attributed to any component failure which makes it hard for analysis to pin-point weak component if used.

- Transformer 3-phase $11 / 0.415 \mathrm{kV}, 500 \mathrm{kVA}$

- Circuit breaker $11 \mathrm{kV}, 550 \mathrm{~A}$

- Switch gear 350A

- HRC fuse 350A

- Incoming feeder $11 \mathrm{kV}, 902 \mathrm{Jkg}^{-1} \mathrm{~K}^{-1}$

- Outgoing feeder $0.415 \mathrm{kV}, 902 \mathrm{Jkg}^{-1} \mathrm{~K}^{-1}$ 
- Overcurrent relay $5 / 1 \mathrm{~A}$

- Earth fault relay $5 / 1 \mathrm{~A}$,

- Switches (3) 25A

- Bus bar $630 \mathrm{~A}, 11 \mathrm{kV}$

- Surge arrester $11 \mathrm{kV}$

\subsection{CASE STUDY}

In the reliability evaluation of power systems, the collection of components failure data could be one of the most difficult jobs because of several reasons [8]. Hence, the study area is chosen because there is access to the data needed for this research work. The raw data is included in Appendix A. Also, the substation supplies relatively large consumers which make outage in the substation a major concern for both the Power Company (Eko electricity) and its consumers. In addition, the following features of the substation highlighted below can be found in many other substations which have been in service for more than 10 years across the country. Hence, this substation is assumed to be a typical substation.

- It's an outdoor substation with overhead lines and transformers mounted on the ground. Thereby exposing most of the components to different weather conditions.

- The HRC fuse that serves as major protection device for the transformer has been replaced with copper strands which are easily replaceable. The size of the strand is usually determined by the utility technical workers.

- It has relatively large number of consumers of which some cannot be accounted for when billing is done.

- Most of the substation components have undergone several repairs due to random failures.

The computed consumer reliability indices using Equation 4 to Equation 8 are shown in Table 2. The major assumption in computing these indices is that interruptions affect all the consumers at once. For instance, when there is single-phase fault on the transformer, it is expected that close to one-third of the consumers will be affected but that is not the case. This is because most consumers have the three single-phase supplies in their residences as a way of ensuring availability of power all the time and whenever any of the phases is out. More so, there is no accurate data describing the number of consumers on each phase of the transformer lines.

\section{INTERPRETATION OF COMPONENT RELIABILITY RESULTS}

The results shown in Table 1 reflect the annual outage time / unavailability (U) of the components. The results show that the component contributing most to interruptions in the substation thereby affecting delivery of electricity to the consumers is the transformer having a value of 0.1181 , followed by the fuse 0.0927 and the outgoing feeder, 0.0593 .

The transformer failure and or faults being a major contributor to the loss of supply to consumers can be as a result of overloading of the transformer because of the number of consumers' loads being served or internal faults due to mechanical faults or faults due to aging. In this case, it can be easily seen that overloading appears to be a major reason why the transformer fails because the fuse, which is a self destructive device, is the second largest contributor to interruptions. And the operation of a fuse is to interrupt excess current which can be as a result of overload. Therefore, in cases when higher rating of the fuse is used in order to prevent its quick rupturing as a result of overload, this brings about transformer failure due to overloading. Hence, it can be deduced that overloading, amongst other things, is a primary cause of transformer failure in the substation. The other reason for the transformer failure includes insulation failure and ageing.

Also, among other factors that affect the outgoing feeder, the foremost is overloading which makes the lines to sag due to fault current which is higher than the normal current thereby increasing the probability of the lines coming in contact during a windy weather. Also, lines become annealed and eventually break as a result of reduced tensile strength brought about by higher currents flowing through the lines making them to exceed their thermal capacity.

The least component that fails is the surge arrester having no record of failure throughout the year. This implies that the substation is well protected against voltage surges that may arise as a result of lightning, fault or switching operation.

Earth fault relay and overcurrent relay have lower values of unavailability, $4.9057 \times 10^{-5}$ and $1.8668 \times 10^{-5}$ respectively. This implies that they contributed least to loss of supply and this may be due to the fact that these components are upstream on the feeder leg that feeds this substation and faults downstream of the transformer i.e. low voltage side, have been interrupted by protective device downstream. The relays and breakers are to protect the distribution feeder leg that is incoming to the distribution substation. The bus bar and breaker also had low values of unavailability of $7.7203 \times 10^{-4}$ and $1.4 \times 10^{-3}$ respectively. 
Figures 3 to Figure 5 give a graphical representation of these basic reliability indices.

Table 1: Basic Reliability Indices on Each Component

\begin{tabular}{|l|l|l|l|}
\hline Component & Failure Rate (f/yr) & $\begin{array}{l}\text { Average Outage } \\
\text { Time (Hours) }\end{array}$ & $\begin{array}{l}\text { Annual Outage Time } \\
\text { (Hours) }\end{array}$ \\
\hline Transformer & 0.0031 & 38.1667 & 0.1181 \\
\hline Switch gear & 0.0044 & 6.4167 & 0.0280 \\
\hline Supply line (Incoming ) & 0.0022 & 5.8333 & 0.0126 \\
\hline Bus bars & 0.00046322 & 1.6667 & 0.00077203 \\
\hline Circuit Breakers & 0.00068324 & 2.0833 & 0.0014 \\
\hline Fuses & 0.0061 & 15.1667 & 0.0927 \\
\hline Switches & 0.00045923 & 1.3333 & 0.00061231 \\
\hline Outgoing feeder & 0.0045 & 13.2500 & 0.0593 \\
\hline Overcurrent relay & 0.00023547 & 0.2083 & 0.000049057 \\
\hline Earth fault relay & 0.00011201 & 0.1667 & 0.000018668 \\
\hline Surge Arrester & 0 & 0 & 0 \\
\hline
\end{tabular}

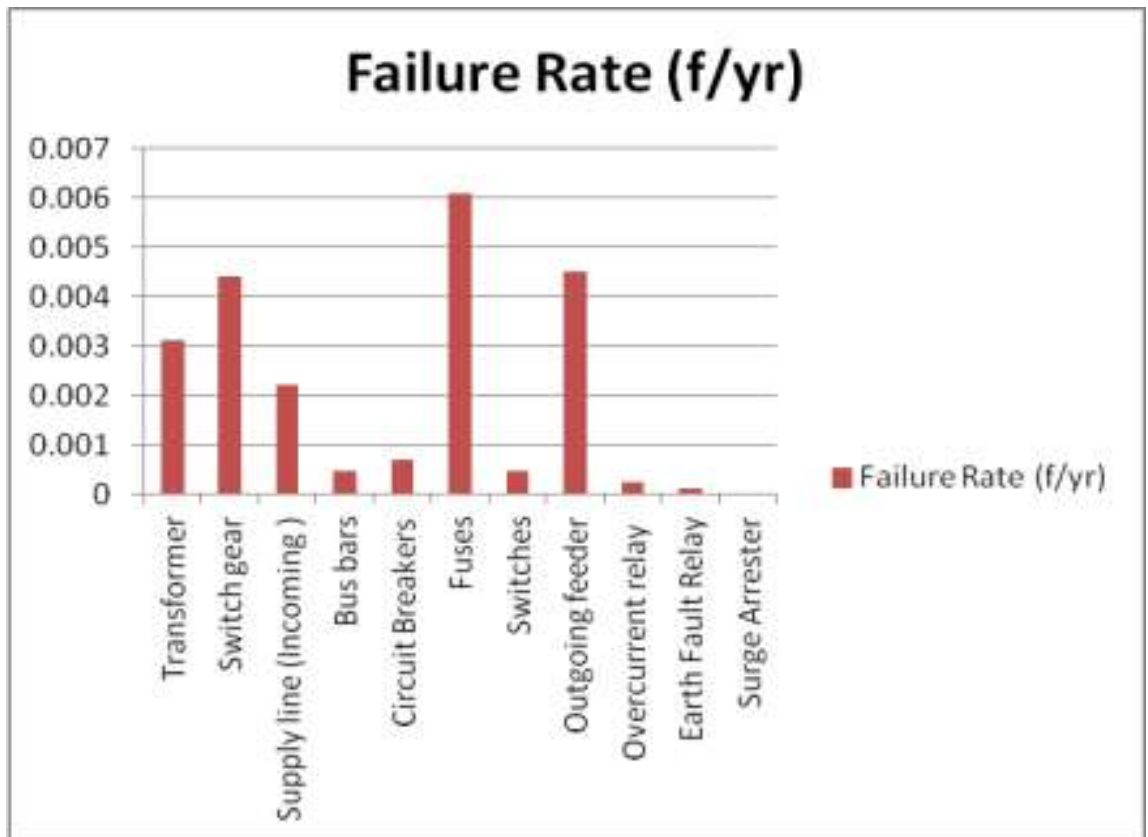

Figure 3: Bar Chart Showing the Failure Rate of Each Component

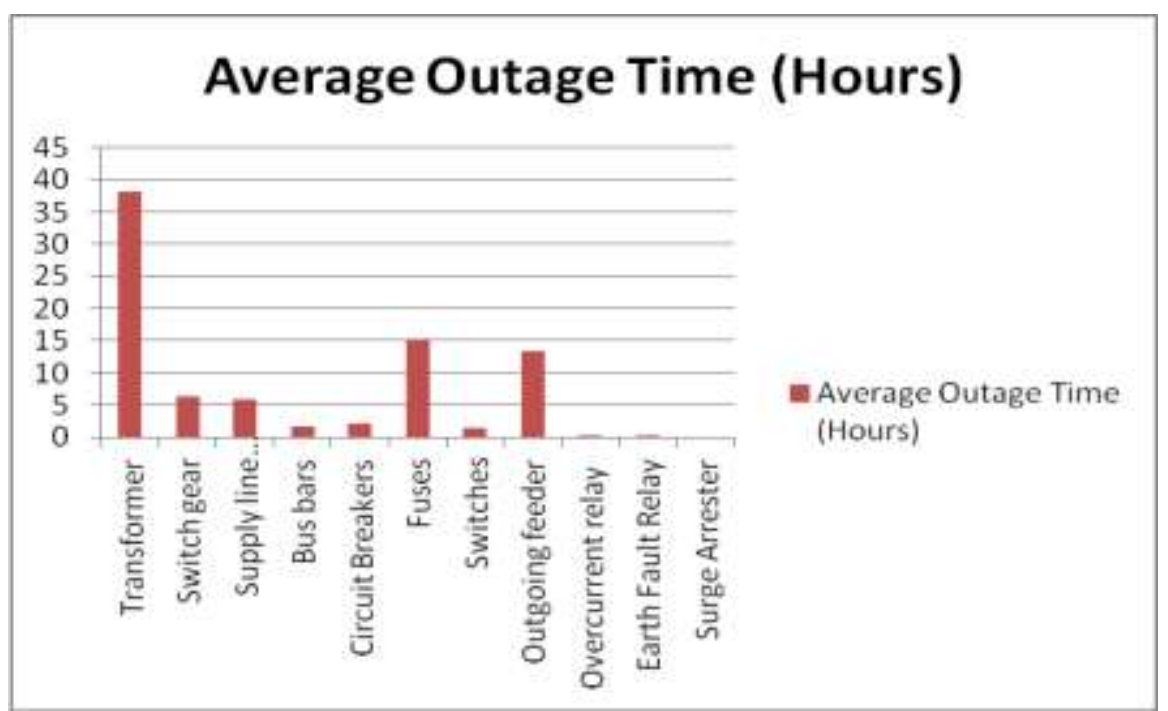

Figure 4: Bar Chart Showing the Average Outage Time of Each Component 


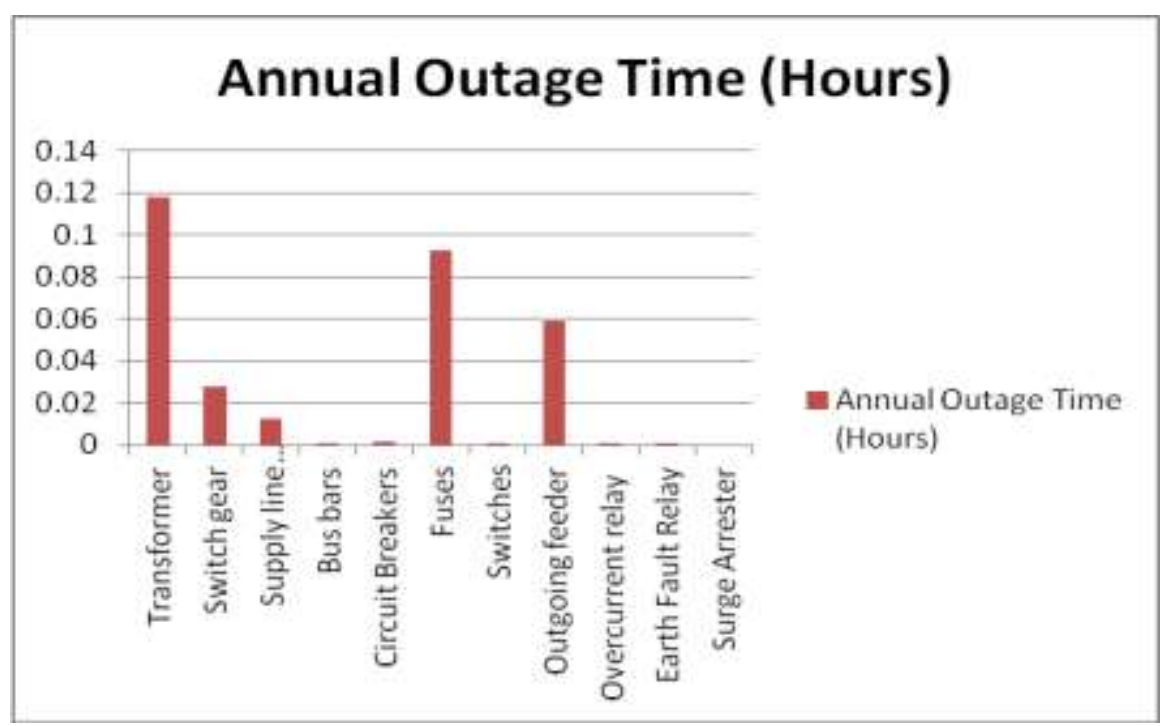

Figure 5: Bar Chart Showing the Annual Outage Time of Each Component

\section{INTERPRETATION OF CONSUMER RELIABILITY INDICES RESULTS}

From Table 2, the average outage duration, SAIDI, for each consumer served is 3.8004 hours for the whole year. This is more than twice the IEEE standard 1366-2003 which gives a value of 1.5hours for North American Utility. This is a region that has sufficient power generation and robust system security. Therefore, according to the standard, the performance of this distribution substation system is very low. February followed by January have the highest SAIDI values of 1.0000 and 0.9701 respectively. December followed by June have the lowest SAIDI values of 0.0634 and 0.1045 respectively. This implies that the causes of interruptions were quickly identified and the faults cleared early enough in December and June. This substation has a very acceptable low value of SAIFI for the year. This means that the frequency of interruptions spread across the year is actually low. Considering the SAIFI value alone, the system could have been mistaken to be very reliable which is not so. January and February have highest values of 0.1418 and 0.1194 respectively whilst the month of December had the lowest SAIFI value followed by June with each having SAIFI values of 0.0187 and 0.0299 respectively.

A CAIDI value of 5.25 implies that from the consumer end, there was no supply of electricity for 5.25 hours every day for the whole year i.e. on the average, it takes 5.25 hours to restore power supply whenever there is interruption. In other words, an interruption lasts for an average of 5.25 hours throughout the year. The month of February followed by January had the highest monthly CAIDI values of 8.3750 and 6.8421 respectively which imply that in February it takes an average of 8.375 hours to restore power supply while for January it takes an average of 6.84 hours. The month of May had the lowest CAIDI value followed by December with each having CAIDI values of 3.1000 and 3.4000 respectively. From the results in Table 3, the distribution substation has service or system reliability index, an ASAI value, of $88.41 \%$. Utilities have been recorded to have a value of $99.99 \%$ or four nines, which means a SAIDI of 52 minutes per annum or 0.866 hour per year ${ }^{1}$ [9]. Hence, with the value calculated for this substation, the reliability is very poor. The highest value recorded in the whole year was in December with a value of $0.9772(97.72 \%)$ while the least value was recorded in the month of February with a value of $0.6149(61.49 \%)$. The ASUI value gives the complement of ASAI by providing the value of the substation unavailability. The system has an ASUI of 0.1159 .

Table 2: Computed Customer Orientation Indices, January to December 2016 on Ayetoro 1 Substation

\begin{tabular}{|l|l|l|l|l|l|l|l|l|l|}
\hline Month & $\begin{array}{l}\text { Frequency of } \\
\text { interruptions }\end{array}$ & $\begin{array}{l}\text { Duration } \\
\text { of } \\
\text { interruption }\end{array}$ & $\begin{array}{l}\text { Total } \\
\text { Hours }\end{array}$ & $\begin{array}{l}\text { No. of } \\
\text { Consumers }\end{array}$ & $\begin{array}{l}\text { SAIDI } \\
\text { (hrs/ } \\
\text { cons) }\end{array}$ & $\begin{array}{l}\text { SAIFI } \\
\text { (int/ } \\
\text { cons) }\end{array}$ & $\begin{array}{l}\text { CAIDI } \\
\text { (hrs/ } \\
\text { cons) }\end{array}$ & $\begin{array}{l}\text { ASAI } \\
\text { (p.u) }\end{array}$ & $\begin{array}{l}\text { ASUI } \\
\text { (p.u) }\end{array}$ \\
\hline January & 38 & 260 & 744 & 268 & 0.9701 & 0.1418 & 6.8421 & 0.6505 & 0.3495 \\
\hline February & 32 & 268 & 696 & 268 & 1.0000 & 0.1194 & 8.3750 & 0.6149 & 0.3851 \\
\hline March & 19 & 76 & 744 & 268 & 0.2836 & 0.0709 & 4.0000 & 0.8978 & 0.1022 \\
\hline April & 22 & 96.5 & 720 & 268 & 0.3601 & 0.0821 & 4.3864 & 0.8660 & 0.1340 \\
\hline May & 10 & 31 & 744 & 268 & 0.1157 & 0.0373 & 3.1000 & 0.9583 & 0.0417 \\
\hline June & 8 & 28 & 720 & 268 & 0.1045 & 0.0299 & 3.5000 & 0.9611 & 0.0389 \\
\hline July & 10 & 44 & 744 & 268 & 0.1642 & 0.0373 & 4.4000 & 0.9409 & 0.0591 \\
\hline August & 13 & 48 & 744 & 268 & 0.1791 & 0.0485 & 3.6923 & 0.9355 & 0.0645 \\
\hline September & 9 & 33 & 720 & 268 & 0.1231 & 0.0336 & 3.6667 & 0.9542 & 0.0458 \\
\hline
\end{tabular}

${ }^{1}$ This value is gotten when this formula is used i.e. ASAI $=(8760-\mathrm{SAIDI}) / 8760$ 
Reliability Analysis of Secondary Distribution System in Nigeria: A Case Study of Ayetoro 1

\begin{tabular}{|l|l|l|l|l|l|l|l|l|l|}
\hline October & 15 & 70 & 744 & 268 & 0.2612 & 0.0560 & 4.6667 & 0.9059 & 0.0941 \\
\hline November & 13 & 47 & 720 & 268 & 0.1754 & 0.0485 & 3.6154 & 0.9347 & 0.0653 \\
\hline December & 5 & 17 & 744 & 268 & 0.0634 & 0.0187 & 3.4000 & 0.9772 & 0.0228 \\
\hline Total & 194 & 1018.5 & 8784 & 268 & 3.8004 & 0.7239 & 5.2500 & 0.8841 & 0.1159 \\
\hline
\end{tabular}

\section{COMPARISON OF THIS STUDY'S RESULTS WITH RELIABILITY BENCHMARK} INDICES

The standard with which reliability of a distribution system is measured against is known as reliability benchmarks. The standards are given in order to provide a justification and give acceptable margin for the reliability performance of distribution networks. Based on IEEE Guide, reference [10] highlighted the benchmarks for nine countries computed for power distribution reliability as shown in Table 4 while the authors included the results from this work in the table too.

From Table 3, Ayetoro 1 substation has a SAIDI of approximately 228 minutes per year, SAIFI of 0.7239, CAIDI of 315 minutes per outage and an ASAI of $88.41 \%$. This substation has an incredibly low and acceptable value of SAIFI which means fewer interruptions and a high value of SAIDI which means longer duration of outages. The ASAI value also shows that the availability of the system is very low. Comparing this with the average reliability indices computed, it is obvious that the substation has worse performance and needs to be improved upon to increase its reliability indices. Figure 6 gives a graphical representation of the comparison.

Table 3: Reliability Indices Benchmark (Rouse and Kelly 2011)

\begin{tabular}{|l|l|l|l|l|}
\hline Country & $\begin{array}{l}\text { SAIDI } \\
\text { (Minutes/year) }\end{array}$ & $\begin{array}{l}\text { SAIFI (Interruptions/ } \\
\text { Consumer) }\end{array}$ & $\begin{array}{l}\text { CAIDI } \\
\text { (Minutes/Outage) }\end{array}$ & ASAI (\%) \\
\hline United States & 240 & 1.5 & 123 & 99.91 \\
\hline UK & 90 & 0.8 & 100 & 99.964 \\
\hline Italy & 58 & 2.2 & 106 & 99.9991 \\
\hline Spain & 2.2 & 114 & 99.968 \\
\hline Austria & 04 & 0.9 & 112 & 99.97 \\
\hline Netherlands & 0.3 & 75 & 99.97 \\
\hline Denmark & 33 & 0.5 & 70 & 99.981 \\
\hline France & 24 & 1 & 58 & 99.97 \\
\hline Ayetoro 1 (Nigeria) & $\mathbf{2 2 8}$ & $\mathbf{0 . 7 2 3 9}$ & $\mathbf{3 1 5}$ & $\mathbf{8 8 . 4 1}$ \\
\hline
\end{tabular}

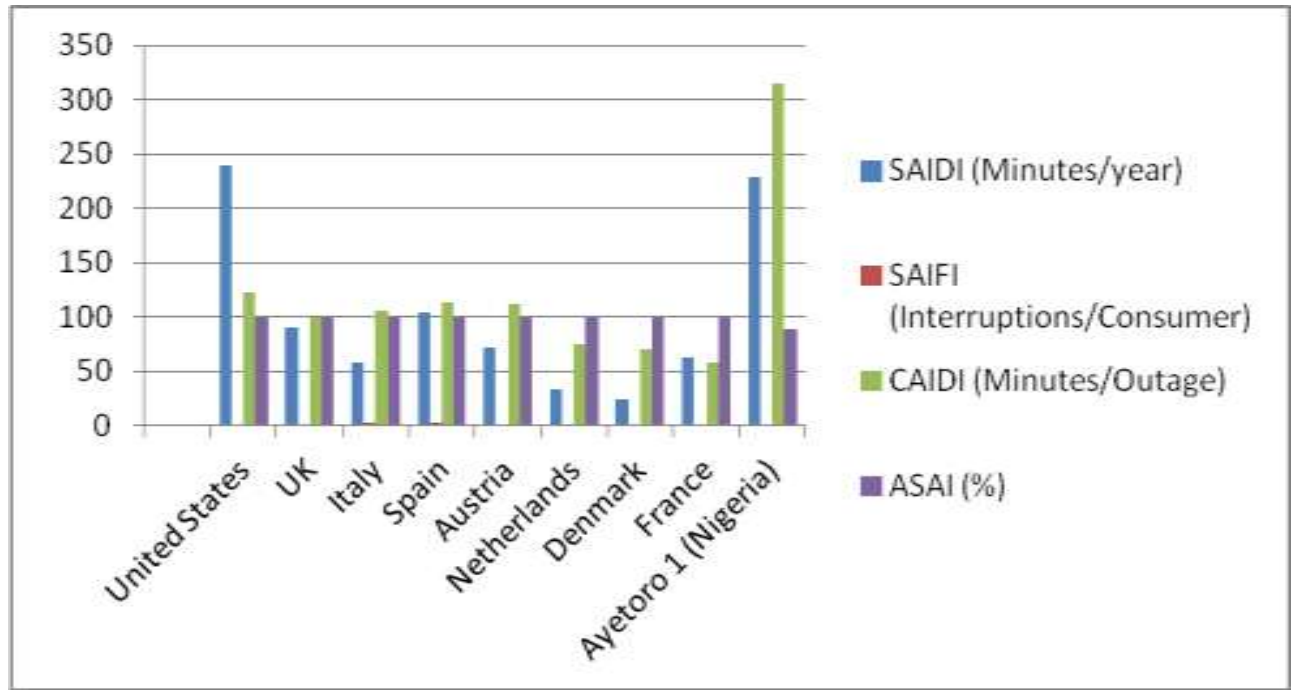

Figure 6: Bar Chart Showing Compared Reliability Indices

\section{VII.CONCLUSION}

In this work, Ayetoro 1 substation was chosen as a secondary distribution substation to study in order to evaluate the reliability of a typical substation in Nigeria representing a lower middle income country. In order to achieve this, the substation was viewed to be in isolation from the rest of the power system. That is, the effect of insufficient generation was not considered and the impact of transmission subsystem failure which may arise as a result was also not considered.

This work has shown that among the different components making up the distribution substation system, the component contributing most to consumer reliability problems is the transformer. Hence, effort needs to be directed in such ways as to adequately protect the transformer from failures. Also, since most transformer 
failures take longer hours to repair or replace, its outage is really significant and should be kept significantly low by ensuring that the protective devices are fully functional. Furthermore, overloading has been identified as a major cause of transformer failure, the reliability of the substation can be improved by providing another substation which will accommodate transferring some of the loads from the present substation.

It is important to note that the frequency of interruption is low which implies that the substation has a satisfactory value of SAIFI but needs to work on reducing the duration of the outages i.e. SAIDI and CAIDI. The main challenge, therefore, is that the substation needs to intensify efforts in reducing the duration of outages in order to improve the availability and reliability of the substation. Therefore, it is not just component outages that affect the distribution substation reliability but the time it takes to restore the components back to service. Moreover, the significantly low value of SAIFI for the substation should not be mistaken to mean better reliability performance because a component that is out of service cannot fail. Hence, the reason for the incredibly low value of SAIFI by the substation due to high value of CAIDI.

Based on the work done and which is reported in this paper, the following recommendations are made:

- The utility company should continue to keep accurate record of interruptions, their causes and durations as these will really help to carry out concise research work.

- Also, efforts should be put in place to see that when there is a component outage, the duration is reduced greatly in order to achieve a more reliable system. And this can be done by ensuring that the consumers have a means of reporting outages to the utility company and speedy response whenever outages are reported. This might mean having more hands on deck, i.e. more manpower to sufficiently cover the different areas. Digital monitoring of the substation and lines as it is done for transmission lines and substations is suggested.

- The consumers should be enlightened to see the substation as their property as this will foster quick reportage of failures. This will also aid in protection of the substation from vandals.

- There have been reported cases of consumers tampering with the substation components. An example is employing the services of a technician to fix fuse related problems. And in many cases, it has proved to be dangerous as the fuse ratings used are higher in a bid to ensure that there is no loss of supply but this affects the transformers in many cases as through faults.

- The design of the substation can be improved to be a double-end fed radial system to ensure better supply of electricity which automatically improves the reliability of the substation.

- Overloading seems to be a major problem for most distribution substations; hence utility company should have accurate data of their consumers. And for newer substations, there must be a major consideration and effective design to accommodate more consumers as the substation continues to exist. Also, building more consumer distribution substations will help reduce the overloading of the transformer.

- Proper and regular inspection of utility facilities like poles will also improve reliability of the substation.

\section{REFERENCES}

[1] B.L. Theraja and A.K. Theraja, A Textbook Of Electrical Technology, New Delhi: S. Chand \& Company Ltd., 2005

[2] R. Billinton and R. N. Allan, Reliability Evaluation of Power Systems, New York and London: Plenum Press, 1996.

[3] T. Gonen, Electric Power Distribution Engineering, Boca Raton: CRC Press, Taylor and Francis Group, 2014.

[4] R. Billinton and S. Jonnavithula, A Test System For Teaching Overall Power System Reliability Assessment, IEEE Transactions on Power Systems, Vol. 11, No. 4, 1996: 1670-1676.

[5] E. Lakervi and E.J. Holmes, Electricity Distribution Network Design, IEE Power Engineering Series 21, Peter Peregrinius, 1995.

[6] R. Anthony, Reliability Analysis Of Distribution Network, Master of Science Thesis, Faculty of Electrical and Electronic Engineering, Universiti Tun Hussein Onn, Malaysia, 2014

[7] R. E. Brown, Electric Power Distribution Reliability, Boca Raton, Florida: CRC Press, 2009.

[8] F. Wang, Reliability Evaluation of Substations Subject to Protection Failures, Master of Science Thesis, Department of Electrical Engineering, Mathematics and Computer Science, Division of Electrical Power System, Delft University Of Technology, Delft, the Netherlands, 2012

[9] R. Uhunmwangho, and E. Omorogiuwa, Reliability Prediction of Port Harcourt Electricity Distribution Network Using NEPLAN, The International Journal Of Engineering And Science, Volume 3, Issue 12, 2014: 68-79.

[10] G. Rouse, and J. Kelly, Electricity Reliability: Problems, Progress and Policy Solutions, 2011. 


\section{APPENDIX A}

Reliability Data of Distribution Substation for Twelve Months (2016) Ayetoro 1 Substation, Aguda, Lagos State.

\begin{tabular}{|c|c|c|c|c|c|c|}
\hline \multirow[t]{2}{*}{ Components } & \multicolumn{2}{|l|}{ January } & \multicolumn{2}{|l|}{ February } & \multicolumn{2}{|l|}{ March } \\
\hline & No. of failures & $\begin{array}{l}\text { Outage } \\
\text { Time (Hours) }\end{array}$ & No. of failures & $\begin{array}{l}\text { Outage } \\
\text { Time (Hours) }\end{array}$ & No. of failures & $\begin{array}{l}\text { Outage } \\
\text { Time (Hours) }\end{array}$ \\
\hline Transformer & 10 & 186 & 8 & 207 & 4 & 38 \\
\hline Supply line & 3 & 10 & 1 & 4 & Nil & Nil \\
\hline Busbars & Nil & Nil & 1 & 6 & Nil & Nil \\
\hline Circuit Breakers & Nil & Nil & Nil & Nil & Nil & Nil \\
\hline Switches & Nil & Nil & Nil & Nil & 1 & 3 \\
\hline Outgoing Feeder & 3 & 26 & 7 & 19 & 2 & 9 \\
\hline Overcurrent Relay & Nil & Nil & 1 & 2 & Nil & Nil \\
\hline Earth Fault Relay & Nil & Nil & Nil & Nil & Nil & Nil \\
\hline Surge Arrester & Nil & Nil & Nil & Nil & Nil & Nil \\
\hline
\end{tabular}

\begin{tabular}{|l|l|l|l|l|l|l|}
\hline \multirow{2}{*}{ Components } & \multicolumn{2}{|c|}{ April } & May & \multicolumn{2}{c|}{ June } \\
\cline { 2 - 6 } & No. of failures & $\begin{array}{l}\text { Outage } \\
\text { Time (Hours) }\end{array}$ & No. of failures & $\begin{array}{l}\text { Outage } \\
\text { Time (Hours) }\end{array}$ & No. of failures & $\begin{array}{l}\text { Outage } \\
\text { Time (Hours) }\end{array}$ \\
\hline Transformer & Nil & Nil & 1 & 8 & Nil & Nil \\
\hline Switchgear & 4 & 18 & Nil & Nil & Nil & Nil \\
\hline Supply line & 5 & 17 & Nil & Nil & Nil & Nil \\
\hline Busbars & Nil & Nil & Nil & Nil & 1 & 6 \\
\hline Circuit Breakers & 2 & 13 & 3 & 12 & Nil & Nil \\
\hline Fuses & 7 & 32 & Nil & 11 & 2 & 14 \\
\hline Switches & Nil & Nil & 16 & 6 & Nil & Nil \\
\hline Outgoing Feeder & 3 & 0.5 & Nil & Nil & Nil \\
\hline Overcurrent Relay & 1 & Nil & Nil & Nil & Nil \\
\hline Earth Fault Relay & Nil & Nil & Nil & Nil \\
\hline Surge Arrester & Nil & & & Nil \\
\hline
\end{tabular}

\begin{tabular}{|c|c|c|c|c|c|c|}
\hline \multirow[t]{2}{*}{ Components } & \multicolumn{2}{|l|}{ July } & \multicolumn{2}{|l|}{ August } & \multicolumn{2}{|l|}{ September } \\
\hline & No. of failures & $\begin{array}{l}\text { Outage } \\
\text { Time (Hours) }\end{array}$ & No. of failures & $\begin{array}{l}\text { Outage } \\
\text { Time (Hours) }\end{array}$ & No. of failures & $\begin{array}{l}\text { Outage } \\
\text { Time (Hours) }\end{array}$ \\
\hline Transformer & Nil & Nil & 2 & 14 & 1 & 6 \\
\hline Switchgear & Nil & Nil & Nil & Nil & Nil & Nil \\
\hline Supply line & 3 & 10 & Nil & Nil & 1 & 5 \\
\hline Busbars & Nil & Nil & 1 & 8 & 2 & 6 \\
\hline Circuit Breakers & Nil & Nil & Nil & Nil & Nil & Nil \\
\hline Fuses & 5 & 18 & 9 & 23 & Nil & Nil \\
\hline Switches & Nil & Nil & Nil & Nil & 1 & 6 \\
\hline Outgoing Feeder & 2 & 16 & 1 & 3 & 4 & 10 \\
\hline Overcurrent Relay & Nil & Nil & Nil & Nil & Nil & Nil \\
\hline Earth Fault Relay & Nil & Nil & Nil & Nil & Nil & Nil \\
\hline Surge Arrester & Nil & Nil & Nil & Nil & Nil & Nil \\
\hline
\end{tabular}

\begin{tabular}{|c|c|c|c|c|c|c|}
\hline \multirow[t]{2}{*}{ Components } & \multicolumn{2}{|l|}{ October } & \multicolumn{2}{|l|}{ November } & \multicolumn{2}{|l|}{ December } \\
\hline & No. of failures & $\begin{array}{l}\text { Outage } \\
\text { Time (Hours) }\end{array}$ & No. of failures & $\begin{array}{l}\text { Outage } \\
\text { Time (Hours) }\end{array}$ & No. of failures & $\begin{array}{l}\text { Outage } \\
\text { Time (Hours) }\end{array}$ \\
\hline Transformer & Nil & Nil & 1 & 6 & Nil & Nil \\
\hline Switchgear & Nil & Nil & 2 & 8 & Nil & Nil \\
\hline Supply line & 4 & 15 & 2 & 9 & Nil & Nil \\
\hline Busbars & Nil & Nil & Nil & Nil & Nil & Nil \\
\hline Circuit Breakers & 1 & 3 & Nil & Nil & 2 & 3 \\
\hline Fuses & 8 & 35 & 1 & 5 & Nil & Nil \\
\hline Switches & Nil & Nil & 2 & 7 & Nil & Nil \\
\hline Outgoing Feeder & 1 & 15 & 5 & 12 & 3 & 14 \\
\hline Overcurrent Relay & Nil & Nil & Nil & Nil & Nil & Nil \\
\hline Earth Fault Relay & 1 & 2 & Nil & Nil & Nil & Nil \\
\hline Surge Arrester & Nil & Nil & Nil & Nil & Nil & Nil \\
\hline
\end{tabular}

Surge Arrester
Ayodeji A. Akintola. " Reliability Analysis of Secondary Distribution System in Nigeria: A Case Study of Ayetoro 1 Substation, Lagos State. " The International Journal of Engineering and Science (The IJES) 6.7 (2017): 13-21 